Seyahat ve Otel İşletmeciliği Dergisi/

Journal of Travel and Hospitality Management

16 (3), 2019, 352-365.

Gönderim Tarihi: 09.11.2018

Kabul Tarihi:30.07.2019

\title{
Türkiye'nin Önemli Turizm Kentlerindeki Havalimanlarının Etkinliklerinin Veri Zarflama Analizi Yöntemiyle Ölçülmesi
}

\section{A Efficiencies Evaluate of the Airports Which in Turkey's Important Tourism Cities with Data Envelopment Analysis}

Dr. Öğr. Üyesi Nilay KÖLEOĞLU

Çanakkale Onsekiz Mart Üniversitesi

Biga İktisadi ve İdari Bilimler Fakültesi

E-posta: nkoleoglu@yahoo.com
Arş. Gör. Esra DEMiREL

Çanakkale Onsekiz Mart Üniversitesi

Biga Uygulamalı Bilimler Fakültesi

E-posta: esrademirel@comu.edu.tr

\section{Öz}

Türkiye'de turizm endüstrisinden elde edilen kazanç milli gelire önemli bir katkı yapmaktadır. Bu sektörden kazanılan gelirin büyük kısmı hava yoluyla gelen yabancı turistlerden sağlanmaktadır. Dolayısıyla havalimanlarının turizm açısından verimli şekilde kullanılması, milli gelirimizi yukarıya taşıyan kriterlerden biri olarak ortaya çıkmaktadır. Bu çalışmada, 2015 yılında Türkiye'nin turizm açısından önemli şehirlerinde bulunan havalimanlarının Veri Zarflama Analizi (VZA) yöntemi ile etkinliklerinin ölçülerek girdilerde yapılması gereken değişiklikler konusunda bilgi vermek amaçlanmaktadır. Havalimanlarında çalışan personel sayısı, personel gideri, uçuş sayısı ve terminal yolcu kapasitesi girdi olarak; turist sayısı ve turizm geliri çıktı değişkeni olarak alınarak BCC girdi yönelimli VZA modeliyle havalimanlarının etkinlikleri ölçülmüştür. Çalışma sonuçlarına göre; Analize konu olan 16 havalimanından İstanbul Atatürk, Muğla Dalaman, Muğla Milas Bodrum, Isparta, Nevşehir Kapadokya ve Denizli havalimanları etkin bulunmuştur.

Anahtar Kelimeler: Veri Zarflama Analizi (VZA), BCC Modeli, girdi yönelimli, etkinlik.

\section{Abstract}

Earnings from the tourism industry in Turkey makes an important contribution to national income. Most of the income from this sector fund from foreign tourists who come by air. Therefore, the efficient use of airports in terms of tourism emerges as one of the criteria to carry our national income upwards. In this study, in 2015 efficiencies evaluate of the airports which in Turkey's important tourism cities with Data Envelopment Analysis (DEA) to aim provide information about changes of inputs to be made. Number of personnel working at airports, personnel departure, number of flights and terminal passenger capacity as inputs; the number of tourists and the tourism revenue output variable are taken and the efficiencies of the airports are evaluated with the BCC input-oriented DEA model. According to the results of the study, Istanbul Ataturk, Mugla Dalaman, Mugla Milas Bodrum, Isparta, Nevsehir Cappadocia and Denizli airports are found effective in the 16 airports analyzed.

Key Words: Data Envelopment Analysis (DEA), BCC Model, input-oriented, efficiency. 


\section{Giriş}

Havacılık sektörü dünya çapında çok hızlı gelişim göstererek, uluslararası ve kıtalararası bütünleşmede önemli bir konuma ulaşmıştır. Son yıllarda dış ticaret ve turizm gibi dünya ekonomisinin gidişatını etkileyen sektörlerin can bulmasını sağlayan alanın yolcu ve kargo taşıyan havacılık sektörü olduğu söylenebilir (UDHB, 2017; 317). Dünya ekonomisinin geleceğine yön veren, düzenleyen ve hızla gelişen sektörlerden biri olarak gösterilen turizm endüstrisi (Kandemir, 2018: 657-668), Türkiye Seyahat ve Acenteleri Birliği'nin yayınladığı istatistiklere göre 2018 yılında ihracattaki payının \% 17,5 olması nedeniyle Türkiye için önemli bir gelir kaynağı oluşturduğu söylenebilir (TURSAB, 2019).

Küreselleşen dünya ekonomilerinde dikkat çeken bir unsur, gelişmekte olan ülkeler için hizmet ve turizm sektörlerinin ekonomik büyümeye sağladığı katkıların gittikçe artan bir öneme sahip olması, bu iki sektöre olan yönelimin hız kazandırdığını ortaya koymasıdır (İşleyen vd., 2018: 957). Coğrafi konumu göz önüne alındığında her yıl dünyanın değişik bölgelerinden birçok turistin Türkiye'ye gelmesi de tesadüf olmamaktadır. Buna bağlı olarak turizm gelirinin büyük çoğunluğu yabancı turistlerden elde edildiği görülmektedir. Kültür ve Turizm Bakanlığı'nın verilerine göre 2015 yılında gelen 36.244.632 yabancı turistin 26.807.722'si havayoluyla ülkemize giriş yapmıştır (Kültür ve Turizm Bakanlığı, 2015). Dolayısıyla yabancı turistlerin ilgisini çeken kentlerdeki havalimanlarının hizmet kalitesini arttırarak turistlerin beklentilerini karşılaması milli gelirimizi etkileyen faktörlerden biri olarak karşımıza çıkmaktadır.

Turizm yörelerinde havalimanlarının etkin olarak kullanımı sağlamak için, turizmin en yoğun olduğu kentlerdeki havalimanlarının incelemesi çalışmanın amacını oluşturmaktadır. Çalışmada giriş bölümünün ardından literatür taraması yapılmıştır. Yöntem bölümünde, çalışmada kullanılan VZA metodu hakkında bilgiler yer almaktadır. Bulgular bölümünde, havalimanlarına BCC girdi yönelimli VZA modelinin uygulamasına yer verilmiştir. Sonuç bölümünde ise elde edilen sonuçlar yorumlanarak öneriler sunulmuştur.

\section{Literatür taraması}

Araştırmanın literatür taraması yapıldığında (VZA) yönteminin, farklı boyutlardaki girdi ve çıtıları kullanarak göreli etkinlik hesaplamasından dolayı bankacılık, eğitim, havacılık, hastane, borsa üzerinde uygulamalar yoğun olmak üzere birçok alanda çalışma yapıldığı görülmektedir. Bu çalışmalardan bazıları aşağıda verilmiştir:

Gillen ve Lall (2001); çalışmalarında 22 büyük ABD havalimanının etkinliğini pist sayısı, giriş sayısı, uçuş alanı sayısı, terminal alanı, bagaj toplama kemeri sayısı, park yeri sayısı girdi; yolcu sayısı, kargo değerini çıktı alarak ölçmüştür.

Fethi vd. (2003); çalışmalarında işletme maliyeti, uçuş dışı gelirleri girdi; yolcu gelirleri, yolcu harici gelirleri çıktı alarak 17 Avrupa Havalimanının etkinliğini VZA yöntemiyle ölçmüştür.

Kayalıdere ve Kargın (2004); çalışmalarında personel sayısı ve toplam aktifi girdi olarak, net satış ve net karı çıktı olarak seçerek 'MKB' de işlem gören 15 çimento şirketi ve 27 tekstil şirketinin 2002 yılındaki etkinlikleri araştırmıştır. Çalışmanın sonucuna göre üç çimento şirketi ve beş tekstil şirketi etkin bulunmuştur. 
Barros ve Dieke (2007); yaptıkları çalışmada 2001-2003 yılları arasındaki verilerden faydalanarak havalimanlarının finansal ve operasyonel performanslarını incelemiştir. Girdi değişkenleri; iş gücü maliyetleri, sermaye yatıımları ve işletme giderleri, çıktı değişkenleri; uçak sayısı, yolcu sayısı, kargo, havacılık geliri, taşıma geliri ve ticari gelir olmak üzere İtalya'daki 31 havalimanının etkinlikleri hesaplanmıştır. İtalyan havalimanlarının çoğu etkin olarak bulunmuş, etkin olmayan havalimanlarının neden etkin olmadığına dair bilgi verilmiştir.

Barros (2008) çalışmasında; çalışan sayısı girdi, yolcu sayısı çıktı olmak üzere İngiltere' de bulunan 27 havalimanının etkinliğini VZA yöntemiyle ölçmüştür. Babacan ve Özcan (2009) çalışmalarında; Alanya bölgesinde bulunan 22 otelin göreli etkinliklerini ölçmüştür. Girdi olarak; personel sayısı, oda sayısı, animasyon ve oyunlar gideri, yiyecek giderleri, içecek gideri, diğer giderler, çıktı olarak; içecek gelirleri, yemek gelirleri, oyunlardan elde edilen gelirler ve oda gelirleri alınarak 13 otel etkin olarak bulunmuştur.

Behdioğlu ve Özcan (2009) yaptıkları çalışmada; Veri Zarflama Analizi yönteminin iki temel modeli olan CCR ve BCC modellerini açıklayarak uygulama aşamaları hakkında bilgi vermiştir. 1999-2005 yılları arasında kesintisiz çalışan 29 adet bankanın etkinliği ölçülmüştür. Bu bankalara CCR ve BCC modeli ayrı ayrı uygulanmıştır. Sonuç olarak; 2005 yılında CCR modeli kullanılarak yapılan analizde 9 banka, BCC modelinde ise 19 banka etkin olarak bulunmuştur.

Mugera (2013); 29 mandırada iş gücü, inek sayısı ve toprak alanını girdi seçerek; süt ve tereyağı üretimini çıktı seçerek teknik etkinliği ölçmüştür. Bu mandıralardan dokuz tanesi etkin olarak bulunmuştur.

Dugulean ve Dugulean (2015); Romanya'da Transilvanya Üniversitesi'nde 30 akademik bölümün 2014-2015 dönemi performansını ölçmüştür. Bu çalışmada doktora programı sayısı ve bölüm üyelerine ödenen saat ücreti girdi olarak; planlanan yıllık bilimsel araştırma faaliyetlerine ulaşma yüzdesi, doktora öğrencilerinin sayısı, lisans programlarının sayısı, yüksek lisans programlarının sayısı çıktı olarak alınmıştır. 30 akademik bölümün 12 tanesinin etkin olduğu bulunmuştur. Buradan yola çıkarak da Transilvanya Üniversitesi'nin 3 fakültesi etkin bulunmuştur.

Crociata ve Mattoscio (2016); İtalya'yı 20 bölgeye ayırarak bu bölgelerdeki kültürel etkinlik ile geri dönüşüm arasında bağlantı kurarak geri dönüşümün göreli etkinliğini araştırmıştır. Kitap birikintisi, gazete birikintisi, müzeye gitme sayısı, sinemaya gitme sayısı ve klasik müzik konserine gitme sayısı girdi olarak, kişi başına düşen geri dönüşüm çıktı olarak alınmıştır. Sonuç olarak üç bölge etkin olarak bulunmuştur.

Alabdulmenem (2016); Suudi Arabistan'daki 25 üniversitenin göreli etkinliğini araştırmıştır. Çalışmada girdiler; fakülte sayısı, yönetici sayısı, çıktılar; yeni kayıt olan öğrenci sayısı, kayıtlı öğrenci sayısı ve mezun sayısıdır. Bulunan sonuçlara göre incelenen 25 üniversitenin 15 tanesi etkindir.

Bharti ve Chitnis (2016); çalışmalarında Hindistan'da bulunan 89 mikro finans kuruluşunu büyüklüklerine göre küçük, orta ve büyük olmak üzere üç gruba ayırmıştır. Üç grubun ayrı ayrı performanslarını varlık ve işletim masrafı girdi alınarak; geri ödenmemiş kredi ve aktif borçlu sayısı çıktı alınarak ölçülmüştür. Küçük grupta üç tane, orta grupta dört tane, büyük grupta altı tane etkin kuruluş bulunmuştur. 


\section{Araştırmanın Yöntemi}

$\mathrm{Bu}$ çalışma ile Türkiye'nin en çok yabancı turist çeken kentlerinde bulunan havalimanlarının etkinlik ve verimliliği araştırılarak diğer havalimanları arasında performansının ne durumda olduğunun Veri Zarflama Analizi (VZA) yöntemiyle tespit edilmesi amaçlanmıştır. Araştırmanın anakütlesi Türkiye'de yer alan tüm havalimanları oluşturmaktadır. Örneklem ise T.C. Devlet Hava Meydanları İşletmeciliğinin havalimanlarının turizm merkezlerine yapılması öneminin vurgulanması sebebiyle, önemli turizm merkezlerinde yer alan havalimanları olarak belirlenmiştir. Araştırmanın verileri ikincil veri olarak derlemiştir. T. C. Devlet Hava Meydanları İşletmesi Genel Müdürlüğü'nün 2016 yılı faaliyet raporu ve Kültür ve Turizm Bakanlığı'nın sitesindeki istatistiklerden elde edilen verilerle yapılan çalışmanın geçerlilik ve güvenilirliği önemli bulunmaktadır.

\subsection{Veri Zarflama Analizi}

Veri Zarflama Analizi (VZA) tekniği Charnes, Cooper ve Rhodes (CCR) tarafından 1978 yılında karar verme birimlerinin (KVB) üretim etkinliğinin tespit edilmesi ve çok sayıda çıktı üretilmesine karşıı kullanılan çok sayıda girdinin tahmin edilmesi için kullanıımıştır. Charnes, Cooper ve Rhodes bir KVB' nin üretim etkinliğini (CCR etkinlik) referans KVB kümesiyle karşılaştırarak hesaplayan bir doğrusal programlama formülasyonu hazırlamıştır. Banker, Charnes ve Cooper (BCC), 1984 yılında CCR etkinlik ölçümünün, ölçek etkinliğinin ve teknik etkinliğin (BCC etkinlik) ölçülmesinin sonucunda ortaya çıktığını göstermiştir. BCC, teknik etkinliği tahmin etmek ve ölçeğe dönüştürmek için CCR lineer programlama formülasyonunda değişiklik yapmıştır (Banker ve Thrall, 1992: 74).

VZA, çoklu performans ölçümü bakımından eş düzey birimlerin göreli etkinliklerini hesaplayan matematiksel programlama yaklaşımıdır. VZA'da değerlendirilen birimler(örneğin bankalar) KVB olarak adlandırılır ve performans ölçütleri girdi ve çıktı şeklinde gruplandırılır. VZA'nın kullanımı, özellikle girdi ve çıktı arasındaki ilişki bilinmediği durumda büyük kolaylık sağlar (Chen vd., 2006: 1370). VZA, çok sayıda girdiden çok sayıda çıktı üreten KVB'lerinin göreli etkinliğini hesaplayan parametrik olmayan bir yöntemdir. VZA yaklaşımı altında tüm veriler özel sayısal değerler formunda kabul edilir (Cooper vd., 1999: 597).

KVB'lerin etkinliğinin ölçülmesinde VZA'nın üç temel uygulama aşaması vardır (Golany ve Roll, 1989: 238):

1-Analize giriş için KVB'lerin seçilmesi ve tanımlanması

2-Seçilen KVB'lerin göreli etkinliğini amaca uygun şekilde ölçecek girdi ve çıktı faktörlerinin belirlenmesi

3-VZA modellerinin uygulanması ve sonuçların değerlendirilmesi

VZA'nın uygulanmasında hangi KVB'lerin inceleneceği seçildikten sonra ilk adım analizde kıstas olarak kullanılacak girdi ve çıktı kümesini tanımlamaktır. Amaç performans ölçümü ile arasında istatistiksel bir ilişki bulunan girdi ve çıktı kümesi belirlemektir (Sun, 2002: 54). Girdi ve çıktı kümesi uygun şekilde belirlenerek VZA'da hangi modelin uygulanacağına karar verilir ve analiz yapılarak sonuçlar değerlendirilmektedir.

VZA'nın CCR ve BCC olmak üzere iki temel modeli bulunmaktadır. CCR model ölçeğe göre sabit getiri olan durumlarda uygulanırken, BCC model ölçeğe göre 
değişken getiri olduğu durumda uygulanmaktadır. Ayrıca bu modeller girdi ve çıktı yönelimli olmak üzere iki türlü uygulanmaktadır. Girdi yönelimli modellerde çıktı miktarlarında değişiklik yapmadan girdi miktarlarının ne olması gerektiği incelenmektedir. Çıktı yönelimli modellerde ise eldeki girdilerle maksimum çıktı üretilmesi üzerinde çalışılmaktadır (Akyüz vd., 2015: 51-52).

Bu çalışmada çıktı miktarı sabit tutularak girdi miktarlarının nasıl olması gerektiği değişken getiriye göre incelenmektedir. BCC girdi yönelimli VZA modeli kullanılarak havalimanlarının etkinlikleri ölçülmektedir.

BCC Girdi yönelimli VZA modeli şu şekilde ifade edilmektedir:

$$
E_{k}=\min \alpha-\varepsilon \sum_{i=1}^{m} s_{i}^{-}-\varepsilon \sum_{r=1}^{p} s_{r}^{+}
$$

Kısıtlar şöyledir:

$$
\begin{gathered}
\sum_{j=1}^{n} X_{i j} \lambda_{j}+s_{i}^{-}-\alpha X_{i k}=0 \quad i=1, \ldots, m \\
\sum_{j=1}^{n} Y_{i j} \lambda_{j}-s_{r}^{+}-Y_{r k}=0 \quad r=1, \ldots, p \\
\sum_{j=1}^{n} \lambda_{j}=1 \\
\lambda_{j} \geq 0, \quad j=1, \ldots, n ; s_{i}^{-} \geq 0, \quad i=1, \ldots, m ; s_{r}^{+} \geq 0, \quad r=1, \ldots, p
\end{gathered}
$$

Bu modelde;

$E_{k}:$ KVB'nin etkinliğini,

$X_{i j}:$ j'nci KVB'nin i'nci girdisi,

$X_{i k}$ : k'ncı KVB'nin i'nci girdisi,

$Y_{i j}$ : j'nci KVB'nin i'nci çıktısı,

$Y_{r k}:$ k'ncı KVB'nin r'nci çıktısı,

$\varepsilon$ : Pozitif küçük bir sayı,

n: KVB sayısı, p: Çıktı sayısı, m: Girdi sayısı,

$\alpha$ : KVB'nin azaltılacak olan girdinin miktarını belirten büzülme katsayısı,

$s_{i}$ : KVB'nin maksimal i'nci girdi fazlası,

$s_{r}:$ KVB'nin maksimal r'nci çıktı eksiği,

$\lambda_{j}$ : j'nci KVB'ye karşılık gelen yoğunluk değeri olarak verilmiştir.

BCC modeli için optimum çözüm $\left(E_{k}, \lambda_{j}, s_{i}^{-}, s_{i}^{+}\right), E_{k}=1$ ve $s_{i}^{-}=0$ ile $s_{i}^{+}=0$ şartları sağlanıyorsa KVB, BCC-etkindir; aksi halde BCC-etkin değildir (Cooper vd., 2007: 89). Etkin olmayan KVB'lerin etkin olabilmesi için bulunan referans kümedeki KVB'lerine girdi yönelimli BCC modelinde aşağıdaki matematiksel ifadeyle benzetilir:

$$
X_{K V B}=\sum_{j=1}^{n} X_{i j} \lambda_{j}
$$




\section{Bulgular}

Bu çalışmada Türkiye'nin turizm açısından önemli şehirlerinde bulunan havalimanlarının 2015 yılı performansları ele alınmıştır. Bu havalimanları şunlardır:

Tablo 1: Havalimanlarına Ait Girdi ve Çıktı Verileri

\begin{tabular}{|l|l|l|l|l|l|l|l|}
\hline \multirow{2}{*}{ NO } & HAVALimANLARI & $\begin{array}{l}\text { Personel } \\
\text { Sayısı }\end{array}$ & $\begin{array}{l}\text { Personel } \\
\text { Gideri } \\
\text { (Bin TL) }\end{array}$ & $\begin{array}{l}\text { Uçuş } \\
\text { Sayısı }\end{array}$ & $\begin{array}{l}\text { Yolcu } \\
\text { Kapasitesi } \\
\text { (Milyon) }\end{array}$ & $\begin{array}{l}\text { Turist } \\
\text { Sayısı }\end{array}$ & $\begin{array}{l}\text { Turizm } \\
\text { Geliri } \\
\text { (\$) }\end{array}$ \\
\hline 1 & İstanbul Atatürk & 998 & 79219 & 320816 & 25,5 & 9595597 & 7254271332 \\
\hline 2 & Muğla Dalaman & 339 & 25699 & 19343 & 5 & 1603666 & 1212371496 \\
\hline 3 & Muğla Milas Bodrum & 264 & 19414 & 12805 & 2 & 814793 & 615983508 \\
\hline 4 & Ankara Esenboğa & 883 & 74319 & 15758 & 10 & 366540 & 277104240 \\
\hline 5 & $\begin{array}{l}\text { Izmir Adnan } \\
\text { Menderes }\end{array}$ & 654 & 51639 & 20837 & 10 & 927343 & 701071308 \\
\hline 6 & Antalya & 575 & 44492 & 123766 & 36 & 10435098 & 788934088 \\
\hline 7 & Bursa & 155 & 11001 & 349 & 2,25 & 5175 & 3912300 \\
\hline 8 & Adana & 370 & 26839 & 7886 & 3 & 173624 & 131259744 \\
\hline 9 & Gaziantep & 221 & 15695 & 1416 & 4 & 25961 & 19626516 \\
\hline 10 & Isparta & 90 & 6289 & 1072 & 1,5 & 82578 & 62428968 \\
\hline 11 & Konya & 169 & 10891 & 806 & 3,5 & 19128 & 14460768 \\
\hline 12 & Trabzon & 239 & 17057 & 2335 & 1,5 & 38009 & 28734804 \\
\hline 13 & Nevşehir Kapadokya & 101 & 6804 & 107 & 0,7 & 1130 & 854280 \\
\hline 14 & Denizli & 102 & 7101 & 81 & 2,2 & 58 & 43848 \\
\hline 15 & Erzurum & 192 & 13172 & 223 & 2 & 2141 & 1618596 \\
\hline 16 & Kayseri & 8322 & 2056 & 2,5 & 48762 & 36864072 \\
\hline
\end{tabular}

Tablo 1'deki veriler Devlet Hava Meydanları İşletmesi Genel Müdürlüğü'nün 2016 yılı faaliyet raporundan, Kültür ve Turizm Bakanlığı'nın sitesindeki istatistiklerden ve havalimanlarının sitelerinden alınmıştır. Turizm geliri bir turistten 2015 yılında elde edilen ortalama gelir ile turist sayısı çarpılarak elde edilmiştir.

Analizde kullanılacak girdi ve çıktıların doğru seçilmesi çok önemlidir; çünkü girdi ve çıktılarda gerçekleşecek ufak değişiklikler bile sonucu etkilemektedir. Girdi ve çıktılar literatür incelenerek en çok kullanılanlar arasından ve havalimanları ile turizm açısından en doğru sonucu verecek olanlar arasından seçilmiştir. Analizde personel 
sayısı, personel gideri, uçuş sayısı ve terminal yolcu kapasitesi girdi; turist sayısı ve turizm geliri çıktıdır. Girdi ve çıktıların açıklaması Tablo 2.'de gösterilmiştir.

Tablo 2: Analizde Kullanılan Girdi ve Çıktıların Açıklamaları

\begin{tabular}{|l|l|}
\hline GiRDi & AÇıKLAMA \\
\hline Personel Sayısı & Havalimanında çalışan personel sayısı \\
\hline Personel Gideri & $\begin{array}{l}\text { Havalimanında çalışan personele ödenen ücretler ve } \\
\text { diğer giderler (Bin TL) }\end{array}$ \\
\hline Uçuş SayıSı & Dış hat gelen-giden uçak sayısı \\
\hline $\begin{array}{l}\text { Terminal Yolcu } \\
\text { Kapasitesi }\end{array}$ & Dış hatlar terminali yolcu kapasitesi (Milyon) \\
\hline ÇIKTI & $\begin{array}{l}\text { Kente yurtdışından havalimanını kullanarak gelen turist } \\
\text { sayısı }\end{array}$ \\
\hline Turist Sayısı & $\begin{array}{l}\text { Kente havalimanını kullanarak gelen turistlerden elde } \\
\text { edilen ortalama gelir (\$) }\end{array}$ \\
\hline Turizm Geliri & \\
\hline
\end{tabular}

Tablo 1'de gösterilen havalimanlarının etkinliklerinin ölçümü Excel DEA Solver ile yapılmıştır. Programda değişken ölçek varsayımı altında çalışan girdi yönelimli BCC modeli ile havalimanlarının etkinlikleri ölçülmüş olup programın verdiği sonuçlar Şekil 1 'de gösterilmiştir. Girdi yönelimli BCC modeli ile girdiler azaltılarak var olan çıktı seviyesinin değişmemesi sağlanmaktadır.

Şekil 1: Havalimanlarının Etkinlik Sonuçları ve Referans Kümeleri

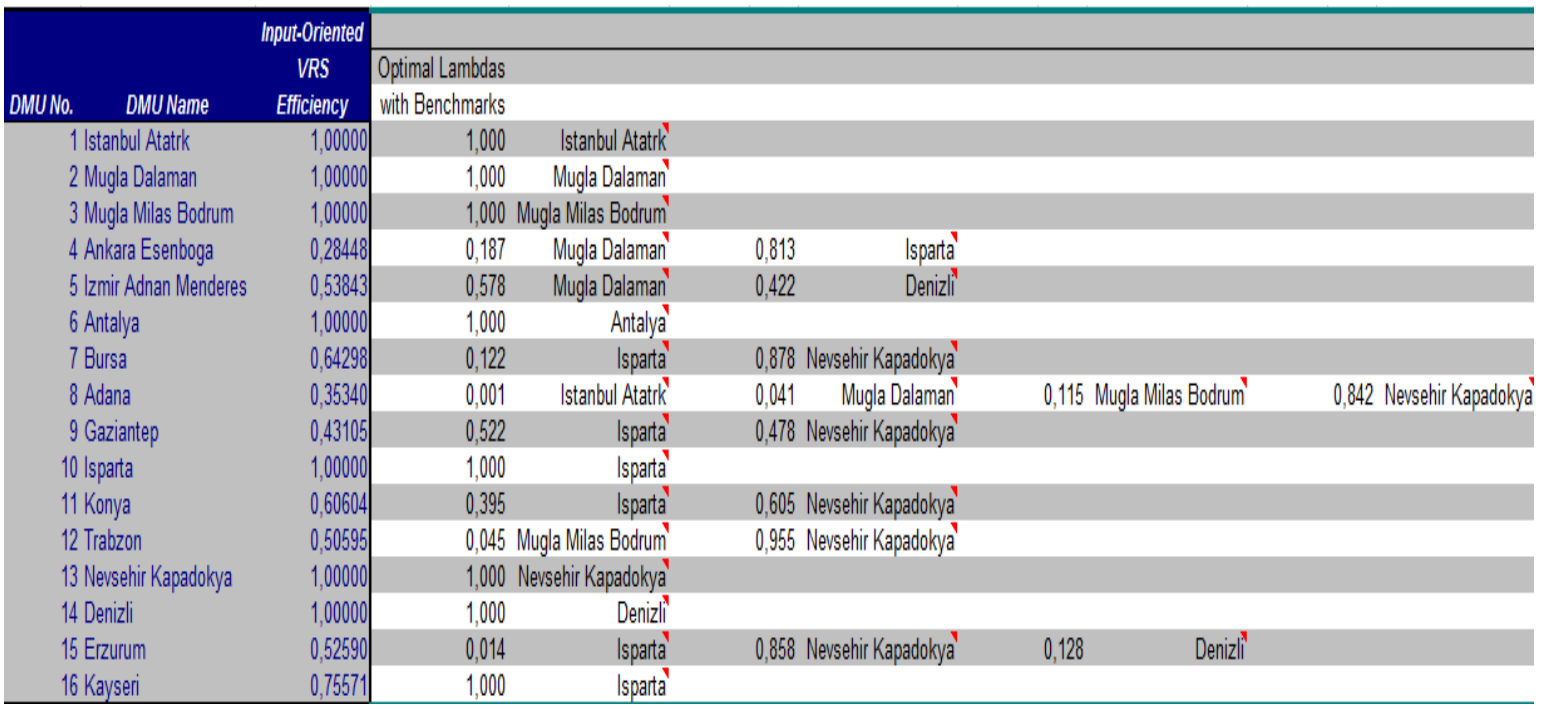

Şekil 1'de verilen programın ölçtüğü teknik etkinlik değerlerine göre İstanbul Atatürk, Muğla Dalaman, Muğla Milas Bodrum, Antalya, Isparta, Nevşehir Kapadokya ve Denizli havalimanları etkin olarak bulunmuştur. Etkinlik değerleri aşağıdaki grafikte gösterilmiştir. Grafikte Tablo 1'de verilen numaralar havalimanlarının sembolü olarak kullanılmıştır. Şekil 2' de görüleceği üzere Ankara Esenboğa en düşük etkinliğe sahip havalimanıdır. Bu havalimanından sonra Adana ve Gaziantep etkinsiz kullanılan havalimanları olarak karşımıza çıkmaktadır. 
Şekil 2: Etkinlik Değerleri

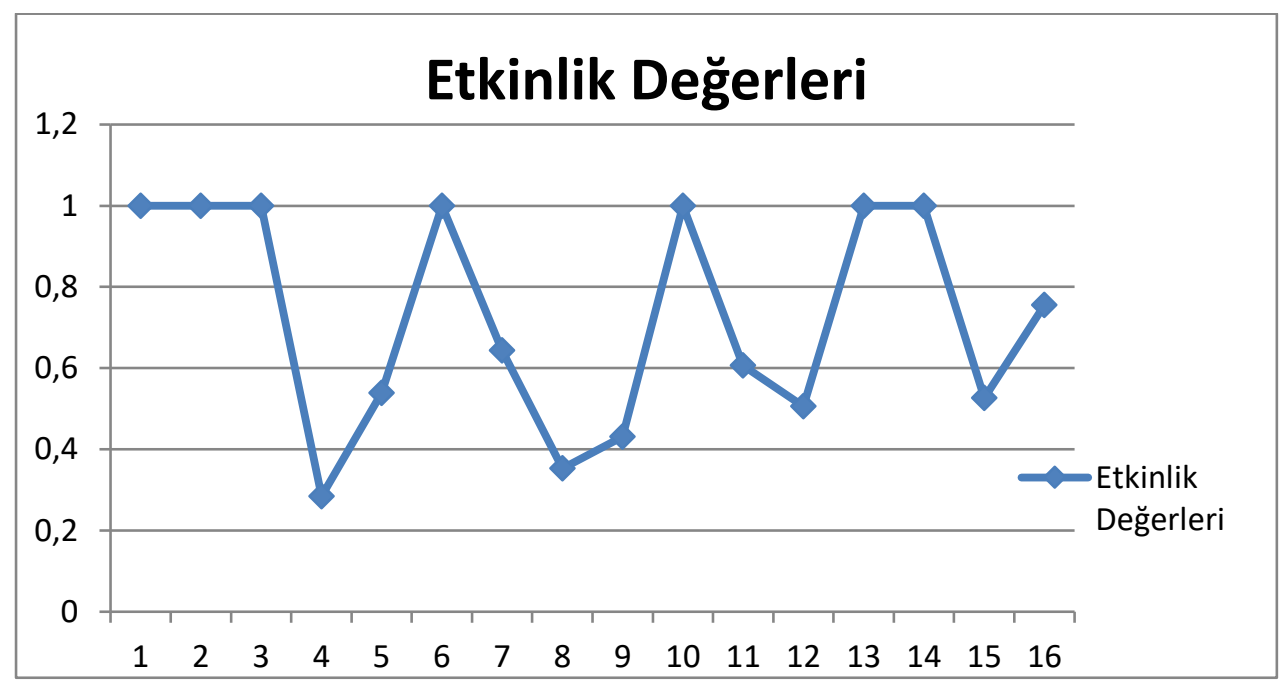

Etkin olmayan havalimanları için referans olarak etkin havalimanları Şekil 1'de görülmektedir. Buna göre Ankara Esenboğa havalimanının referans kümesi Muğla Dalaman ve Isparta havalimanlarıdır. İzmir Adnan Menderes havalimanının referans kümesi Muğla Dalaman ve Denizli havalimanlarıdır. Bursa, Gaziantep ve Konya havalimanlarının referans kümesi Isparta ve Nevşehir Kapadokya havalimanlarıdır. Adana havalimanının referans kümesi İstanbul Atatürk, Muğla Dalaman, Muğla Milas Bodrum ve Nevşehir Kapadokya iken Trabzon havalimanının Muğla Milas Bodrum ve Nevşehir Kapadokya'dır. Erzurum havalimanının referans kümesi Isparta, Nevşehir Kapadokya ve Denizli havalimanlarıdır. Etkin havalimanlarının diğer havalimanlarının etkin olması için kaç kere referans oldukları Tablo 3'te gösterilmiştir.

Tablo 3: Referans Havalimanı ve Referans Olma Sayısı

\begin{tabular}{|l|c|}
\hline Havalimanı Adı & Referans OIma Sayısı \\
\hline İstanbul Atatürk & 1 \\
\hline Muğla Dalaman & 3 \\
\hline Muğla Milas Bodrum & 2 \\
\hline Isparta & 6 \\
\hline Nevşehir Kapadokya & 6 \\
\hline Denizli & 2 \\
\hline
\end{tabular}

Şekil 1'de etkin olmayan havalimanları için referans kümelerinde yer alan havalimanlarının yoğunluk değerleri $\lambda$ ile gösterilmiştir. Yoğunluk değerleri ve referans havalimanları etkin olmayan karar verme birimlerinin hedef değerlerinin hesaplanmasında kullanılmaktadır. Modelimiz girdi yönelimli BCC model olduğu için sadece girdiler için ulaşılması gereken hedefler (4) eşitliğiyle bulunmaktadır.

Ankara Esenboğa havalimanın referans kümesindeki Muğla Dalaman için $\lambda_{1}=0,187$; Isparta için $\lambda_{2}=0,813$ ' tür. Bu değerlerle Ankara Esenboğa havalimanının hedef girdileri şu şekilde hesaplanmaktadır:

$X_{\text {Ankara Esenboğa }}=\left(X_{1}, X_{2}, X_{3}, X_{4}\right)=\{(339 ; 25699 ; 19343 ; 5) \times 0.187+(90 ; 6289 ; 1072 ; 1.5) \times 0.813\}$ $=(136.563 ; 9918.67 ; 4488.677 ; 2.1545)$ 
İzmir Adnan Menderes havalimanın referans kümesindeki Muğla Dalaman için $\lambda_{1}=0,578$; Denizli için $\lambda_{2}=0,422$ ' dir. Bu değerlerle İzmir Adnan Menderes havalimanının hedef girdileri şu şekilde hesaplanmaktadır:

$X_{\text {IzmirAdnanMenderes }}=\left(X_{1}\right.$,
$\left.X_{4}\right)=\{(339 ; 25699 ; 19343 ; 5) \times 0.578+(102 ; 7101 ; 81 ; 2.2) \times 0.422\}$ $=(238.986 ; 17850.644 ; 11214.436 ; 3.8184)$

Bursa havalimanın referans kümesindeki Isparta için $\lambda_{1}=0,122$; Nevşehir Kapadokya için $\lambda_{2}=0,878$ ' dir. Bu değerlerle Bursa havalimanının hedef girdileri şu şekilde hesaplanmaktadır:

$$
\begin{aligned}
X_{\text {Bursa }}=\left(X_{1}, X_{2}, X_{3}, X_{4}\right)=\left\{\begin{array}{c}
(90 ; 6289 ; 1072 ; 1.5) \times 0.122+(101 ; 6804 ; 107 ; 0.7) \times 0.878\} \\
=(99.658 ; 6741.17 ; 224.73 ; 0.7976)
\end{array}\right.
\end{aligned}
$$

Adana havalimanın referans kümesindeki İstanbul Atatürk için $\lambda_{1}=0,001$; Muğla Dalaman için $\lambda_{2}=0,041$; Muğla Milas Bodrum için $\lambda_{3}=0,115$; Nevşehir Kapadokya için $\lambda_{4}=0,842$ ' dir. Bu değerlerle Adana havalimanının hedef girdileri şu şekilde hesaplanmaktadır:

$X_{\text {Adana }}=\left(X_{1}, X_{2}, X_{3}, X_{4}\right)=\{(998 ; 79219 ; 320816 ; 25.5) \times 0.001+(339 ; 25699 ; 19343 ; 5) \times 0.041$ $+(264 ; 19414 ; 12805 ; 2) \times 0.115+(101 ; 6804 ; 107 ; 0.7) \times 0.842\}$

$$
=(130.299 ; 9094.456 ; 2676.548 ; 1.0499)
$$

Gaziantep havalimanın referans kümesindeki Isparta için $\lambda_{1}=0,522$; Nevşehir Kapadokya için $\lambda_{2}=0,478$ ' dir. Bu değerlerle Gaziantep havalimanının hedef girdileri şu şekilde hesaplanmaktadır:

$$
\begin{aligned}
X_{\text {Gaziantep }}=\left(\mathrm{X}_{1}, \mathrm{X}_{2}, \mathrm{X}_{3}, \mathrm{X}_{4}\right)= & \{(90 ; 6289 ; 1072 ; 1.5) \times 0.522+(101 ; 6804 ; 107 ; 0.7) \times 0.478\} \\
& =(95.258 ; 6535.170 ; 610.73 ; 1.1176)
\end{aligned}
$$

Konya havalimanın referans kümesindeki Isparta için $\lambda_{1}=0,395$; Nevşehir Kapadokya için $\lambda_{2}=0,605^{\prime}$ dir. Bu değerlerle Konya havalimanının hedef girdileri şu şekilde hesaplanmaktadır:

$$
\begin{aligned}
X_{\text {Konya }}=\left(X_{1}, X_{2}, X_{3}, X_{4}\right)=\{ & (90 ; 6289 ; 1072 ; 1.5) \times 0.395+(101 ; 6804 ; 107 ; 0.7) \times 0.605\} \\
& =(96.655 ; 6600.575 ; 488.175 ; 1.016)
\end{aligned}
$$

Trabzon havalimanın referans kümesindeki Muğla Milas Bodrum için $\lambda_{1}=0,045$; Nevşehir Kapadokya için $\lambda_{2}=0,955^{\prime}$ dir. Bu değerlerle Trabzon havalimanının hedef girdileri şu şekilde hesaplanmaktadır:

$$
\begin{aligned}
X_{\text {Trabzon }}=\left(X_{1}, X_{2}, X_{3}, X_{4}\right)= & \{(264 ; 19414 ; 12805 ; 2) \times 0.045+(101 ; 6804 ; 107 ; 0.7) \times 0.955\} \\
& =(108.335 ; 7371.45 ; 678.41 ; 0.7585)
\end{aligned}
$$

Erzurum havalimanın referans kümesindeki Isparta için $\lambda_{1}=0,014$; Nevşehir Kapadokya için $\lambda_{2}=0,858$; Denizli için $\lambda_{3}=0,128$ ' dir. $\mathrm{Bu}$ değerlerle Erzurum havalimanının hedef girdileri şu şekilde hesaplanmaktadır:

$X_{\text {Erzurum }}=\left(X_{1}, X_{2}, X_{3}, X_{4}\right)=\{(90 ; 6289 ; 1072 ; 1.5) \times 0.014+(101 ; 6804 ; 107 ; 0.7) \times 0.858$ $+(102 ; 7101 ; 81 ; 2.2) \times 0.128\}$

$$
=(100.974 ; 6834.806 ; 117.182 ; 0.9032)
$$

Şekil 3'te Excel DEA Solver'ın etkin olmayan havalimanları için bulduğu hedef girdi değerleri verilmiştir. Yukarıda referans kümesinden ve yoğunluk değerleri $\lambda^{\prime} y ı$ 
kullanarak hesapladığımız hedef girdiler ile tabloda verilen programın bulduğu değerlerin hemen hemen aynı olduğu görülmektedir.

Şekil 3: Havalimanlarının Hedef Girdi Değerleri

\begin{tabular}{|l|llll|}
\hline \multirow{2}{*}{ DMU No. DMU Name } & Efficient Input Target & & & \\
& Personel Say & Personel Gideri & Ucus Say & Terminal Yolcu Kapasitesi \\
\hline 1 Istanbul Atatrk & 998,00000 & 79219,00000 & 320816,00000 & 25,50000 \\
2 Mugla Dalaman & 339,00000 & 25699,00000 & 19343,00000 & 5,00000 \\
3 Mugla Milas Bodrum & 264,00000 & 19414,00000 & 12805,00000 & 2,00000 \\
4 Ankara Esenboga & 136,48419 & 9912,52633 & 4482,89385 & 2,15339 \\
5 Izmir Adnan Menderes & 228,28809 & 17068,80639 & 11219,23557 & 3,44381 \\
6 Antalya & 575,00000 & 44492,00000 & 123766,00000 & 36,00000 \\
7 Bursa & 99,66176 & 6741,34627 & 224,39972 & 0,79733 \\
8 Adana & 130,75697 & 9130,05946 & 2786,89044 & 1,06019 \\
9 Gaziantep & 95,26213 & 6535,36355 & 610,36734 & 1,11730 \\
10 Isparta & 90,00000 & 6289,00000 & 1072,00000 & 1,50000 \\
11 Konya & 96,65163 & 6600,41710 & 488,47086 & 1,01625 \\
12 Trabzon & 108,38792 & 7375,54398 & 682,53255 & 0,75892 \\
13 Nevsehir Kapadokya & 101,00000 & 6804,00000 & 107,00000 & 0,70000 \\
14 Denizli & 102,00000 & 7101,00000 & 81,00000 & 2,20000 \\
15 Erzurum & 100,97294 & 6834,76132 & 117,27587 & 0,90331 \\
16 Kayseri & 90,00000 & 6289,00000 & 1072,00000 & 1,50000 \\
\hline
\end{tabular}

Şekil 3'te verilen hedef girdilerden personel sayısı ve uçuş sayısı tam sayı değeri almak zorundadır. Virgülden sonraki kısımlar ihmal edilerek gerçek değerler ve hedef değerler Tablo 4'de gösterilmiştir.

Tablo 4: Havalimanlarının Gerçek Değerleri ve Hedef Değerleri

\begin{tabular}{|l|c|c|c|c|c|c|c|c|}
\hline & \multicolumn{9}{|c|}{ Gerçek Değerler } & \multicolumn{4}{c|}{ Hedef Değerler } \\
\cline { 2 - 9 } Havalimanları & $\begin{array}{l}\text { Personel } \\
\text { Sayısı }\end{array}$ & $\begin{array}{l}\text { Personel } \\
\text { Gideri } \\
\text { (Bin TL) }\end{array}$ & $\begin{array}{l}\text { Uçuş } \\
\text { Sayısı }\end{array}$ & $\begin{array}{l}\text { Terminal } \\
\text { Yolcu } \\
\text { Kapasitesi } \\
\text { (Milyon) }\end{array}$ & $\begin{array}{l}\text { Personel } \\
\text { Sayısı }\end{array}$ & $\begin{array}{l}\text { Personel } \\
\text { Gideri } \\
\text { (Bin TL) }\end{array}$ & $\begin{array}{l}\text { Uçuş } \\
\text { Sayısı }\end{array}$ & $\begin{array}{l}\text { Yolcu } \\
\text { Kapasitesi } \\
\text { (Milyon) }\end{array}$ \\
\hline $\begin{array}{l}\text { Istanbul } \\
\text { Atatürk }\end{array}$ & 998 & 79219 & 320816 & 25,5 & 998 & 79219 & 320816 & 25,5 \\
\hline $\begin{array}{l}\text { Muğla } \\
\text { Dalaman }\end{array}$ & 339 & 25699 & 19343 & 5 & 339 & 25699 & 19343 & 5 \\
\hline $\begin{array}{l}\text { Muğla Milas } \\
\text { Bodrum }\end{array}$ & 264 & 19414 & 12805 & 2 & 264 & 19414 & 12805 & 2 \\
\hline $\begin{array}{l}\text { Ankara } \\
\text { Esenboğa }\end{array}$ & 883 & 74319 & 15758 & 10 & 136 & 9912,52633 & 4482 & 2,15339 \\
\hline $\begin{array}{l}\text { İzmir Adnan } \\
\text { Menderes }\end{array}$ & 654 & 51639 & 20837 & 10 & 228 & 17068,80639 & 11219 & 3,44381 \\
\hline Antalya & 575 & 44492 & 123766 & 36 & 575 & 44492 & 123766 & 36 \\
\hline Bursa & 155 & 11001 & 349 & 2,25 & 99 & 6741,34627 & 224 & 0,79733 \\
\hline Adana & 370 & 26839 & 7886 & 3 & 130 & 9130,05946 & 2786 & 1,06019 \\
\hline Gaziantep & 221 & 15695 & 1416 & 4 & 95 & 6535,36355 & 610 & 1,1173 \\
\hline Isparta & 90 & 6289 & 1072 & 1,5 & 90 & 6289 & 1072 & 1,5 \\
\hline Konya & 169 & 10891 & 806 & 3,5 & 96 & 6600,4171 & 488 & 1,01625 \\
\hline Trabzon & 239 & 17057 & 2335 & 1,5 & 108 & 7375,54398 & 682 & 0,75892 \\
\hline $\begin{array}{l}\text { Nevşehir } \\
\text { Kapadokya }\end{array}$ & 101 & 6804 & 107 & 0,7 & 101 & 6804 & 107 & 0,7 \\
\hline Denizli & 102 & 7101 & 81 & 2,2 & 102 & 7101 & 81 & 2,2 \\
\hline Erzurum & 192 & 13172 & 223 & 2 & 100 & 6834,76132 & 117 & 0,90331 \\
\hline Kayseri & 122 & 8322 & 2056 & 2,5 & 90 & 6289 & 1072 & 1,5 \\
\hline
\end{tabular}


İstanbul Atatürk, Muğla Dalaman, Muğla Milas Bodrum, Antalya, Isparta, Nevşehir Kapadokya ve Denizli Havalimanları etkin olarak bulunmasından dolayı gerçek değerler ve hedef değerleri aynıdır. Ankara Esenboğa Havalimanı'nın etkin olabilmesi için 883 olan personel sayısını 136'ya, 74319 olan personel giderini 9912,52633 'e, 15758 olan uçuş sayısını 4482'ye, 10 olan terminal yolcu kapasitesini 2,15339'e indirilmesi gerekmektedir. İzmir Adnan Menderes Havalimanı'nın etkin olabilmesi için 654 olan personel sayısını 228'e, 51639 olan personel giderinin 17068,80639'e, 20837 olan uçuş sayısının 11219'a, 10 olan terminal yolcu kapasitesinin 3,44381'e indirilmesi gerekmektedir. Bursa Havalimanı'nın etkin olabilmesi için 155 olan personel sayısını 99'a, 11001 olan personel giderini 6741,34627 'e, 349 olan uçuş sayısını 224 'e, 2,25 olan terminal yolcu kapasitesini 0,79733'e indirilmesi gerekmektedir. Adana Havalimanı'nın etkin olabilmesi için 370 olan personel sayısının 130'a, 26839 olan personel giderinin 9130,05946'ya, 7886 olan uçuş sayısının 2786'ya, 3 olan terminal yolcu kapasitesinin 1,06019'a indirilmesi gerekmektedir. Gaziantep Havalimanı'nın etkin olabilmesi için 221 olan personel sayısının 95'e, 15695 olan personel giderinin 6535,36355'ya, 1416 olan uçuş sayısının 610 'a, 4 olan terminal yolcu kapasitesinin 1,1173'a indirilmesi gerekmektedir. Konya Havalimanı'nın etkin olabilmesi için 169 olan personel sayısının 96'ya, 10891 olan personel giderinin 6600,4171 'ya, 806 olan uçuş sayısının 488'e, 3,5 olan terminal yolcu kapasitesinin 1,01625'a indirilmesi gerekmektedir. Trabzon Havalimanı'nın etkin olabilmesi için 239 olan personel sayısının 108'e, 17057 olan personel giderinin 7375,54398 'ya, 2335 olan uçuş sayısının 682'ye, 1,5 olan terminal yolcu kapasitesinin 0,75892'e indirilmesi gerekmektedir. Erzurum Havalimanı'nın etkin olabilmesi için 192 olan personel sayısının 100'e, 13172 olan personel giderinin 6834,76132'e, 223 olan uçuş sayısının 117'ye, 2 olan terminal yolcu kapasitesinin 0,90331'e indirilmesi gerekmektedir. Kayseri Havalimanı' nın etkin olabilmesi için 122 olan personel sayısının 90'a, 8322 olan personel giderinin 6289'a, 2056 olan uçuş sayısının 1072'ye, 2,5 olan terminal yolcu kapasitesinin 1,5'e indirilmesi gerekmektedir.

\section{Sonuç ve Değerlendirme}

Türkiye'de turizm sektörü 1980'li yıllardan sonra yükselişe geçerek işsizliği azaltarak milli gelire önemli bir katkı sağlamaktadır. Böylesine önemli bir sektör olan turizm birçok sektörle bağlantılı bir şekilde ilerlemektedir. Bu sektörler içinde havacılık, yabancı turistleri ülkemize gelmesini sağlamasıyla dikkatleri üzerinde toplamaktadır.

Bu çalışmada 2015 yılında Türkiye'nin turizm sektöründe önemli yer edinmiş 16 kentinin havalimanlarının göreli etkinlikleri veri zarflama analizi yöntemiyle araştırılmıştır. Belirlenen çıktılara müdahale etmek mümkün olmadığından Girdi yönelimli BCC modeli kullanılmıştır. Yapılan analiz sonucunda etkinliklerinin hesaplanması için seçilen 16 havalimanından 6 tanesi etkin olarak bulunmuştur. Bunlar İstanbul Atatürk, Muğla Dalaman, Muğla Milas Bodrum, Antalya, Isparta, Nevşehir Kapadokya ve Denizli Havalimanlarıdır. Etkin olmadığı tespit edilen 10 havalimanı ise Ankara Esenboğa, İzmir Adnan Menderes, Bursa, Adana, Gaziantep, Konya, Trabzon, Erzurum ve Kayseri Havalimanlarıdır. Bu havalimanlarının etkin seviyeye gelebilmesi için hangi girdilerin ne kadar azaltılması gerektiği tespit edilerek hedef girdi değerleri belirlenmiştir.

Kıyıldı ve Karaşahin (2006), yaptıkları çalışmada Türkiye'de sivil hava taşımacılığı yapan 32 havalimanının etkinliğini CCR-VZA modeliyle incelemişlerdir. Bu analizde dokuz adet girdi ve bir adet çıktı kullanılarak 1996-2002 yılları arasında etkinlik ölçümü yapılmıştır. Girdiler Check-in kontuar sayısı, X-ray sayısı, terminal binası yolcu kullanım alanı, otopark araç kapasitesi, havaalanı pist büyüklüğü, 
havaalanı apron büyüklüğü, havaalanı apron uçak kapasitesi, havaalanı taksirut uçak kapasitesi, terminal binası konveyor sayısıdır. Çalışmada tek çıktı 2002 yılı uçak sayısı alınmıştır. Sonuç olarak; 1996, 2000 ve 2001 yıllarında hiç bir havalimanının eldeki verileri etkin kullanmadığı tespit edilmiştir. 1997'de Van, 1998'de Adana ve Trabzon, 1999' a Gaziantep, Şanlıurfa ve Çanakkale, 2002'de ise Kayseri havalimanları etkin bulunmuştur. Etkin olarak bulunan Adana, Trabzon, Gaziantep ve Kayseri havalimanlarını 2015 yılı için turizm sektörü açısından incelendiğinde bu çalışmada etkin olmadığını bulundu.

Peker ve Baki (2009), 2007 yılında havalimanı etkinliklerini VZA yöntemiyle hesaplamıştır. Çalışmada girdi olarak; otopark kapasitesi, pist sayısı, havalimanı büyüklüğü ve çalışan sayısı alınmıştır. Çıktılar; yolcu sayısı ve kargo değeridir. Çalışmanın sonuçlarında Ankara, Antalya, Adana, Kayseri, Trabzon, Malatya ve Çardak havalimanları etkin olarak bulunmuştur. Bu çalışmanın sonuçlarında Ankara, Adana, Kayseri ve Trabzon havalimanları turizm açısından incelenerek etkin olmadığı tespit edildi.

Avcı ve Aktaş (2015), 2013-2014 yıllarındaki verilerle VZA yöntemi kullanarak yaz ve kış dönemlerinde havalimanlarındaki etkinliklerini hesaplayarak karşılaştırmıştır. Girdiler; personel sayısı ve terminal alanıdır. Çıktılar ise yolcu sayısı, yük trafiği ve toplam uçak trafiğidir. Buna göre yaz aylarında en yüksek etkinlik Nevşehir, kış aylarında en yüksek etkinlik Denizli, yaz aylarında en düşük etkinlik Kars ve Sivas, kış aylarında en düşük etkinlik Muğla Dalaman ve Muğla Milas havalimanlarında olduğu bulunmuştur. Bu çalışmada 2015 yılının tüm mevsimlerini dahil ederek Denizli ve Nevşehir Kapadokya havalimanları etkin bulundu. Aynı zamanda tüm yıl incelendiğinde Muğla Dalaman ve Muğla Milas havalimanları da etkin olarak bulunmuştur.

Modelin sonuçlarını analiz ederken dikkate alınması gereken bir konu şudur: \%100 Etkin bulunan havalimanları seçilen girdi ve çıktılara göre ve 16 havalimanı arasında performansı en iyi olarak bulunmuştur. Yani seçilen girdi ve çıktılar ile havalimanlarına göre \%100 etkin olarak bulunan havalimanlarının etkinlik oranları değişiklik gösterebilmektedir. Ayrıca farklı çalışmalarda farklı girdi ve çıktılar kullanılması havalimanı etkinliklerine farklı bakış sağlayacağından diğer araştırmacılara yön gösterebilir. Farklı yıllara göre yapılacak etkinlik değerlendirmesi de diğer araştırmacılar için öneri olarak sunulabilir.

\section{Kaynakça}

Alabdulmenem, F. M. (2016), "Measuring the Efficiency of Public Universities: Using Data Envelopment Analysis (DEA) to Examine Public Universities in Saudi Arabia", International Education Studies, 10 (1), ss.137-143.

Akyüz, K. C., Çamur, G. ve Yıldırım, İ. (2015), "Mobilya ve Levha Sektöründe Veri Zarflama Analizi Yardımıyla Etkinlik Ölçümü”, Turkish Journal of Forestry, 16(1), ss.50-59.

Avcı, T. ve Aktaş, M. (2015), "Türkiye'de Faaliyet Gösteren Havalimanlarının Performanslarının Değerlendirilmesi", Journal of Alanya Faculty of Business/Alanya Isletme Fakültesi Dergisi, 7(3), ss.67-77.

Babacan, A. ve Özcan, S. (2009), "Alanya Bölgesi Otellerinin Göreli Etkinliğinin Belirlenmesi: Bir Veri Zarflama Analizi Tekniği Uygulaması", Mustafa Kemal Üniversitesi Sosyal Bilimler Enstitüsü Dergisi, 6(12), ss.176-189.

Banker, R. D. ve Thrall, R. M. (1992), "Estimation of Returns to Scale Using Data Envelopment Analysis", European Journal of Operational Research, 62(1), ss.74-84. 
Barros, C. P. (2008), "Technical Efficiency of UK Airports", Journal of Air Transport Management, 14(4), ss.175-178.

Behdioğlu, S. ve Özcan, A. G. G. (2009), "Veri Zarflama Analizi ve Bankacılık Sektöründe Bir Uygulama", Süleyman Demirel Üniversitesi Iktisadi ve Idari Bilimler Fakültesi Dergisi, 14(3), ss.301-326.

Bharti, N. ve Chitnis, A. (2016), "Size and Efficiency of MFIs: A Data Envelopment Analysis of Indian MFIs", Enterprise Development and Microfinance, 27(4), ss.255-272.

Chen, Y., Liang, L., Yang, F. ve Zhu, J. (2006), "Evaluation of Information Technology Investment: A Data Envelopment Analysis Approach", Computers \& Operations Research, 33(5), ss.1368-1379.

Cooper, W. W., Park, K. S. ve Yu, G. (1999), "IDEA and AR-IDEA: Models for Dealing with Imprecise Data in DEA", Management Science, 45(4), ss.597-607.

Cooper, W. W., Seiford, L. S. ve Tone, K. (2007), "DEA. A Comprehensive Text with Models", Applications, References and DEA-Solver Software Kluwer Publication, Boston.

Crociata, A. ve Mattoscio, N. (2016), "Output-orientated Data Envelopment Analysis for Measuring Recycling Efficiency: An Application at Italian Regional Level", Environmental Education Research, 22(4), ss.551-570.

DHMi, Devlet Hava Meydanları İşletmesi, 2016 Faaliyet Raporu, 2017, Ankara.

Duguleana, L. ve Duguleana, C. (2015), "Data Envelopment Analysis for the Efficiency of Academic Departments", Bulletin of the Transilvania University of Brasov Economic Sciences. Series V, 8(2), ss.453-468.

Fethi, M.D., Peter, M. ve Jackson T., G. (2003). "Measuring the Efficiency of European Airlines: An Application of DEA and Tobit Analysis", University of Leicester, Leicester, ss.1-32

Gillen, D. ve Lall, A. (2001), "Non-parametric measures of efficiency of US Airports", International Journal of Transport Economics/Rivista Internazionale di Economia dei Trasporti, 28, ss.283-306.

Golany, B. ve Roll, Y. (1989), "An Application Procedure for DEA". Omega, 17(3), ss.237-250.

İşleyen, Ş., Altun, Y. ve Görür, Ç. (2018), "Hizmet İhracatı ve Turizm Harcamalarının Ekonomik Büyümeye Katkısı Üzerine Ampirik Bir Analiz: 1996-2017 Türkiye Örneği”. Anemon Muş Alparslan Üniversitesi Sosyal Bilimler Dergisi, 6(6), 953960.

Kandemir, A.Ş., (2018), "Bulanık Kümeleme Analizi ile Türkiye' deki İllerin Bulanık Kümeleme Analizi ile Sınıflandırılması”, Seyahat ve Otel İşletmeciliği Dergisi,15(3), ss.657-668.

Kayalidere, K. ve Kargın, S. (2004), "Çimento ve Tekstil Sektörlerinde Etkinlik Çalışması ve Veri Zarflama Analizi" Dokuz Eylül Üniversitesi Sosyal Bilimler Enstitüsü Dergisi, 6(1), ss.196-219.

Kıyıldı, R. K. ve Karaşahin, M. (2006), "Türkiye'deki Hava Alanlarının Veri Zarflama Analizi İle Altyapı Performansının Değerlendirilmesi”. Süleyman Demirel Üniversitesi Fen Bilimleri Enstitüsü Dergisi, 10(3), ss.391-397.

Peker, İ. ve Baki, B. (2009), "Veri Zarflama Znalizi ile Türkiye Havalimanlarında Bir Etkinlik Ölçümü Uygulaması", Çukurova Üniversitesi Sosyal Bilimler Enstitüsü Dergisi, 18(2), ss.72-88.

Pestana Barros, C. ve Dieke, P. U. C. (2007), "Performance Evaluation of Italian Airports: A Data Envelopment Analysis", Journal of Air Transport Management, 13(4), ss.184-191.

Sun, S. (2002), "Measuring the Relative Efficiency of Police Precincts Using Data Envelopment Analysis", Socio-Economic Planning Sciences, 36(1), ss.51-71. 
Mugera, A. W. (2013), "Measuring Technical Efficiency of Dairy Farms With Imprecise Data: A Fuzzy Data Envelopment Analysis Approach", Australian Journal of Agricultural and Resource Economics, 57(4), ss.501-520.

T.C. Kültür ve Turizm Bakanlığı, http://www.kultur.gov.tr/, (3.12.2017).

T.C. Kültür ve Turizm Bakanlığı, Yatırım ve İşletmeler Genel Müdürlüğü, Sınır GirişÇıkış İstatistikleri http://yigm.kulturturizm.gov.tr/TR,9854/sinir-giris-cikisistatistikleri.html (3.12.2017). Türkiye Seyahat Acentaları Birliği, https://www.tursab.org.tr/tr/turizm-verileri/istatistikler/turizmin-ekonomidekiyeri/gsmh-icindeki-payi-1963-_79.html (3.12.2017).

UDHB, "Ulaşan ve Erişen Türkiye 2017", Ulaştırma Denizcilik ve Haberleşme Bakanlığı Yayını, Ankara, 2017. 